\title{
TRATAMENTO DE HEMORRAGIA DECORRENTE DE UM PROCEDIMENTO \\ INVASIVO REALIZADO SOBRE UM HEMANGIOMA - RELATO DE UM CASO
}

HAEMORRHAGE TREATMENT AS A RESULT OF AN INVASIVE PROCEDURE DONE IN HEMANGIOMA - RELATE OF A CASE

\author{
Éber L.de L. STÊVÃO*
}

\begin{abstract}
RESUMO
O autor relata um caso de hemorragia crônica proveniente de uma remoção de um tecido exofítico intrabucal num paciente portador de um Hemangioma Plano Cervicofacial Bilateral. Também coloca como imprescindível a necessidade do conhecimento, por parte do cirurgião-dentista, clínico geral, de exames laboratoriais básicos para a avaliação de uma anemia instalada em decorrência da perda sanguínea por procedimentos executados na cavidade bucal e como tratá-la.
\end{abstract}

Palavras-chave: Hemangioma, Nevus Flammeus, Anemia Hipocrômica.

\section{INTRODUÇÃO}

Para um melhor entendimento, faz-se necessário trazer à tona algumas definições e conceitos sobre hemorragia, anemia e hemangioma e qual a interligação ocorrida no caso descrito.

As hemorragias podem ser internas ou externas e visíveis ou ocultas, sendo suas causas demasiadamente numerosas incluindo desde traumatismos até enfermidades que primariamente ou secundariamente atacam as paredes vasculares. Elas acarretam a perda do ferro gerando anemias hipocrônicas. É importante frisar que o significado clínico da hemorragia depende da quantidade de sangue perdido, sua velocidade de escape e local da hemorragia.

\footnotetext{
*Pós-graduado em Cirurgia e Traumatologia Bucomaxilofacial da PUC-RS.
} 
Após uma hemorragia súbita o organismo repõe o plasma dentro de um a três dias, porém a concentração da série vermelha está diminuída que retorna ao normal dentro de três a quatro semanas. A anemia (do grego an, privativo e haima, sangue) etimologicamente significa falta de sanguc. Chega-se a anemia por perda, formação deficiente ou por destruição exagerada de sangue ${ }^{6}$. Interessa-nos a anemia causada pela diminuição da hemoglobina e das hemácias.

As anemias crônicas podem também se instalar pelas hemorragias pequenas e repetidas, sendo chamadas de anemias pós-hemorrágicas crônicas ou anemia hipocrônica-microcítica.

O hemangioma é uma lesão vascular localizada que acomete a pele, tecido subcutâneo e, raras vezes, o sistema nervoso central. Resulta de hiperplasia de vasos sangüíneos, e é também conhecido como um tumor benigno do endotélio dos vasos sangüíneos. É comum, perfazendo $7 \%$ de todos os tumores benignos 8 .

Entre os vários tipos de hemangiomas um em especial se faz necessário abordar. É o Nevus flammeus, que varia de cor desde rosapálido até violeta-escuro e ordinariamente é plano. Pode assumir a forma dita de manchas Port-Wine (manchas em vinho-do-porto).

O hemangioma plano é um tumor permanente e apresenta-se desde o nascimento e pode estar associado a outras síndromes.

As malformações vasculares são o resultado de anormalidades estruturais formadas durante o desenvolvimento fetal.

Histologicamente, mostram apenas dilatação dos vasos da derme, porém muitas vezes atingem tecidos mesodérmicos. Para Young ${ }^{9}$, os hemangiomas são ectasias de capilares circundados por endotélio maturo.

\section{RELATO DE CASO}

O paciente M.H.M. de 63 anos, casado, brasileiro, caucasiano, longelíneo, trabalhador do campo compareceu no plantão no Serviço Odontológico do Pronto Socorro do Hospital Cajuru, em Curitiba, com história de estomatorragia há mais de 30 horas, não profuso, porém contínuo, após ter sofrido remoção de uma massa gengival excedente sangrante, na região edêntula dos incisivos céntrais superiores. 
Segundo o relato dos familiares, um pequeno sangramento na área já se fazia presente há algumas semanas. Após o primeiro procedimento cirúrgico, realizado há dois dias, o paciente sofreu nova intervenção para tratamento da hemorragia, sem sucesso. No dia seguinte retornou e foi encaminhado para a emergência do pronto socorro local, onde recebeu soroterapia e coletou-se sangue para a pesquisa do volume globular, cujo resultado foi $32 \%$. O paciente foi então dispensado sem maiores precauçôes ou receita qualquer. Procuraram-nos no dia seguinte com a situação do paciente se agravando mais.

Ao exame ectoscópico foi constatado a presença de manchas Port-Wine de um Hemangioma Plano Permanente cervicofacial bilateral.

O quadro clínico do paciente era de disfagia, náuseas, vertigem, debilidade geral, palidez das extremidades, fadiga fácil, descontrole emocional, taquicardia, hipotensão, pródromos de anemia por hemorragia.

Os resultados dos sinais vitais foram anotados, sendo a T.A. de 90:60 mmHg, pulso 110 b.p.m., isocoria, respiração superficial levemente acelerada e taquicardia.

Ao exame oroscópico foi constatado a presença de um coágulo sobre suturas localizadas na área de rebordo residual ântero-superior. $\mathrm{O}$ hemangioma se estendia para intrabucal, envolvendo mucosa jugal e gengiva inserida dessa área.

A primeira medida tomada foi buscar outros dados através da anamnese, como a possibilidade da associação do hemangioma com outras síndromes. O paciente relatava a presença de feridas nas mãos $\mathrm{e}$ pés, típicas de um trabalhador braçal, que não cicatrizavam há vários dias. Fol aventada a hipótese do paciente ser um portador de diabetes mellitus. Comentou que nunca sofrera intervenção cirúrgica alguma e negava reações alérgicas a medicamentos, tampouco estava utilizando medicação sistêmica. Na sua história médica pregressa nada constava de antecedentes mórbidos pessoais. Pela ficha de atendimento soubemos que já havia sido tentado anteriormente medidas associadas como esponjas hemostáticas locais, medicamentos coagulantes injetáveis, porém sem sucesso.

Como procedimento cirúrgico local foi feita a remoção de um grande coágulo sobre a ferida e no fundo de vestíbulo da região ântero- 
superior, limpeza com soro fisiológico, remoção das suturas inadequadas e frouxas, com a compressão local por gaze embebida em $\mathrm{H}_{2} \mathrm{O} 2$ (10 volumes). Nova sutura oclusiva com pontos simples e em $U$ foi realizada, mesmo assim não foi possível estancar o sangramento totalmente. Numa etapa seguinte instituímos soroterapia, medicação analgésica e antibiótica profilática via endovenosa. Foram solicitados exames laboratoriais como: Hemograma Completo (HC), Plaquetometria, TP, KTTP, Uréia, Creatinina, Sódio (Na+), Potássio $(\mathrm{k}+)$, Glicemia e Tipagem Sangüínea.

Os resultados dos exames revelaram uma anemia do tipo hipocrômica-microcítica. Valor levemente acima da normalidade para a creatinina e uma trombocitopenia (trombocitose) decorrente do quadro hemático. O resultado da glicose sérica estava dentro da normalidade. O exame clínico mostrou que o paciente não apresentava sinais e sintomas de diabetes. Todos os resultados quanto à crise sangüínea estavam perfeitamente normais, o que descartou qualquer hipótese de coagulopatias ou diáteses hemorrágicas.

Alguns dos resultados mais significativos estão no quadro abaixo:

Quadro 1. Diferença entre os exames pré e pós-atendimento

\begin{tabular}{l|l}
\hline Primeiro Exame & Último Exame \\
\hline Eritrócitos $=3.410 .000 /$ microlitro & $4.140 .000 /$ microlitro \\
Hemoglobina $(\mathrm{Hb})=10,3 \mathrm{~g} / \mathrm{dl}$ & $12,6 \mathrm{~g} / \mathrm{dl}$ \\
Volume Globular $=32 \%$ & $37 \%$ \\
Cocentração Hemoglobina Globular Média $=$ & $34 \%$ \\
$32,1 \%$ & $5.900 / \mathrm{microlitro}$ \\
Leucócitos $=8.000 / \mathrm{microlitro}$ & $207.000 / \mathrm{microlitro}$ \\
Plaçuctas $=100.000 / \mathrm{microlitro}$ & $32 \mathrm{mg} / \mathrm{dl}$ \\
Uréia $=49 \mathrm{mg} / \mathrm{dl}$ & $0,4 \mathrm{mg} / \mathrm{dl}$ \\
\hline
\end{tabular}

Em posse dos resultados, discutiu-se com o médico, cirurgião geral de plantão, a necessidade de papas de hemácias, sendo transfundido duas unidades. Também ficou prescrito Complexo B e Sulfato de Zinco, Vitamina C e Sulfato Ferroso vias endovenosa e oral, respectivamente. 
Mantivemos cabeceira elevada no leito, dieta líquida a pastosa hiperproteica e hipercalórica, fria.

O paciente ficou internado pelo período de 3 dias, sendo realizados no total três exames laboratoriais. O último exame foi pedido no dia anterior ao da alta o que provavelmente caracterizou uma melhora ainda maior do quadro hematológico, antes que o paciente deixasse as dependências do hospital.

\section{CONCLUSÃO}

Os resultados laboratoriais associados com a história do caso clínico e vida médica pregressa do paciente devem ser sempre bem analisados quando se trata de uma hemorragia crônica, principalmente àquelas associadas a malformações artério-venosas.

O exame laboratorial sem um fim específico para o diagnóstico se torna inválido e ineficaz para o tratamento de qualquer processo patológico, como ocorrido no primeiro atendimento. E ć sabido que durante e imediatamente após a hemorragia, elementos do $\mathrm{HC}$, como a Hb e o Hematócrito são enganadoramente altos devido à vasoconstrição.

Os resultados mais positivos no tratamento de qualquer tipo de processo patológico são obtidos quando vemos o paciente como um todo. E é cvidente que não existe o atendimento estanque por parte das especialidades médicas. $\mathrm{O}$ tratamento só foi efetivo quando visto em conjunto, cirurgião-dentista e médico. Portanto, a integralização no atendimento é a conduta ideal a se seguir.

Este paciente por ser idoso, apresenta uma taxa de renovação celular fisiologicamente diminuída. Logo, provavelmente já era portador de uma anemia, devido ao sangramento pré-existente, à afagia (anemia por depleção das reservas de $\mathrm{Fe}$ ) e a compensação megaloblástica (proeritroblástica) lenta, resultando numa eritropoiese deficitária.

O entendimento do resultado de exames laboratoriais mínimos é indispensável para o profissional da Odontologia, quando se está frente a uma hemorragia crônica decorrente de uma cirurgia oral.

Nunca se deve atuar invasivamente sobre angiomas sem um prévio diagnóstico e respaldo técnico-científico quanto às medidas eficazes para o tratamento adequado de tais lesões. 
É sabido que algumas substâncias são essenciais para o bom funcionamento da produção de eritrócitos e reparação tecidual. Entre elas, o ferro, a cianocobalamina, ácido fólico, ácido ascórbico e sulfato de zinco. Daí o principal motivo para a instituição da terapêutica hospitalar por nós assumida.

Esclarecimento das causas de sintomas da face, pescoço e cabeça freqüentemente requer o conhecimento unificado tanto do médico quanto do cirurgião-dentista para que se chegue a um diagnóstico e institua-se a terapia adequada ao caso.

\begin{abstract}
The author reports a case of chronical haemorrhage originated from a intrabucal exofitic tissue removal in one pacient with bilateral cervicofacial Hemangioma. He also emphasizes that general dental clinicians the necessity of knowing basic laboratorial exams to valuate a installed anaemia from a blood lost in procedures done in oral cavity and how to treat it.
\end{abstract}

Key-words: Hemangioma, Nevus Flammeus, Hipochromic Anaemia

\title{
REFERÊNCIAS BIBLIGRÁFICAS
}

BERKOW, R. Manual Merck de Medicina: diagnóstico e tratamento. São Paulo: Editora Roca, 1989.

GRAS, J. Fundanentos de Bioquúmica Médica, 4 ed. Barcelona: Ediciones Toray, 1967.

GUYTON, A.C. Tratado de Fisiologia Médica. 7. ed. Rio de Janeiro: Editora Guanabara Koogan, 1989.

JUNQUEIRA, L.C.; CARNEIRO, J. Histologia básica. 7. ed. Rio de Janeiro: Editora Guanabara Koogan, 1990.

NETTO, A.C. Clínica Cirúrgia. 4 ed. rev. e amp. São Paulo: Editora Sarvier, 1988.

PADILlA, T. Semiologia do rim, baço e sangue. Rio de Janeiro: Editora Guanabara Koogan, 1949.

RIELLA, M.C. Princípios de Nefrologia e Distúrbios Hidroeletrolíticos. 2 ed. Rio de Janeiro: Editora Guanabara Koogan, 1988.

ROBBINS, S.L. Pathologic Basis of Disease. W.B. Saunders Company, 1989. 